\title{
Parametric analysis of dry machining process using a novel integrated multi-attribute decision making approach
}

\author{
G. Venkata Ajay Kumara ${ }^{a^{*}}$ A. Ramaa and M. Shilpa ${ }^{\mathrm{b}}$
}

${ }^{a}$ R.V. College of Engineering, Bengaluru, India

${ }^{b}$ M S Ramaiah Institute of Technology, Bengaluru, India

\begin{tabular}{l}
\hline C H R O N I C L E \\
\hline Article history: \\
Received August 22, 2021 \\
Received in revised format: \\
August 31, 2021 \\
Accepted October 222021 \\
Available online \\
November 15, 2021 \\
\hline Keywords: \\
Dry machining \\
DEMATEL \\
CRITIC \\
TOPSIS \\
EN 24 alloy steel
\end{tabular}

\section{Introduction}

\begin{abstract}
A B S T R A C T
In most of the machining processes, the complexity arises in the selection of the right process parameters, which influence the machining process and output responses such as machinability and surface roughness. In such situations, it is important to estimate the inter-relationships among the output responses. One such method, Decision-Making Trial and Evaluation Laboratory (DEMATEL) is applied to study the inter-relationships of the output responses. Estimation of proper weights is also crucial where the output responses are conflicting in nature. In the current study, DEMATEL technique is used for estimating the inter-relationships for output responses in machining of EN 24 alloy under dry conditions. CRiteria Importance Through Inter-criteria Correlation (CRITIC) method is used to estimate the weights and finally the optimal selection of machining parameters is carried out using Techniques for Order Preference by Similarity to an Ideal Solution (TOPSIS) method. The model developed guides the decision maker in selection of precise weights, estimation of the inter relationships among the responses and selection of optimal process parameters.
\end{abstract}

During the machining process, the friction developed at the tool-workpiece contact, which is generally reduced using a coated cutting tool or a coolant. Using coolants might affect the operator's health, hence dry machining, with coated cutting tool, (Viswanathan et al., 2018) is preferred and is widely used. The primary objective of machining is to obtain high quality and reliable products. Machining is a complex process (Akkuş \& Yaka, 2021); machining parameters optimization is quite important to achieve the desired dimensions of the machined part, and it increases productivity (Shastri et al., 2021). Therefore, in the literature the focus of researchers in machining is on the modeling and optimization of the machining process (Sabiya et al., 2019). It is essential to conduct many machining trials in optimizing the process parameters, which increases manufacturing costs (Shilpa et al., 2020). To avoid these manufacturing costs, the Design of Experiments (DoE) methodology is applied. Some DoE methods based on Taguchi Orthogonal Array (OA) (Gaitonde et al., 2009) and Response Surface Methodology (RSM) (Mir \& Wani, 2018) allow the user to conduct least number of experiments, as well as they are helpful in analyzing the effect of each factor, interaction effects between the process parameters. They also aid to study the effect of each factor and generate mathematical models such as regression equations and predict the optimal process parameters. As machining involves multiple conflicting criteria, it is preferred to adopt Multi Criteria Decision-Making (MCDM) methods for performing optimization. MCDM (Rao \& Patel, 2010) is further divided as Multi-Objective DecisionMaking (MODM) and Multi-Attribute Decision-Making (MADM) methods (Venkata Ajay Kumar G et al., 2019). MODM

* Corresponding author.

E-mail address: ajay.ajay79@gmail.com (G. Venkata Ajay Kumar)

(C) 2022 by the authors; licensee Growing Science, Canada.

doi: $10.5267 / \mathrm{ds} 1.2021 .11 .001$ 
has continuous decision variables, whereas MADM has discrete decision variables. Most commonly used MADM methods are Analytical Hierarchy Process (AHP) (Saaty, 2002), Simple Additive Weighting (SAW) (Kaliszewski \& Podkopaev, 2016), TOPSIS (Lai et al., 1994) and Grey Relational Analysis (GRA) (Julong, 1988).

DEMATEL is used to estimate the interrelationships among the responses and identifying the cause and effects was proposed and designed at the Geneva Research Centre - Battelle Memorial Institute (Si et al., 2018). The researchers (Das \& Chakraborty, 2020) applied the DEMATEL to estimate the interrelationships among the responses of the green electric discharge machining process. The CRITIC method proposed by Diakoulaki, Mavrotas, and Papayannakis (Diakoulaki et al., 1995) is used mainly to determine the objective weights of the responses based on the decision matrix. In machining of ultra-high-strength steel $300 \mathrm{M}$ using four various ceramic tool combinations, (Wang \& Zhao, 2016a) AHP-CRITIC method is applied for mechanical properties optimization of ceramic tool materials. TOPSIS is used for finding out the optimal parametric combination and is widely used in the sustainable turning of 17-4 Precipitated Hardened (PH) stainless steel (Sivaiah \& Uma, 2019) and dry machining of EN AW-2011 alloy (Jozić et al., 2020). Researchers have investigated Surface Roughness (SR), tool wear (flank wear \& crater wear) and chip coefficient reduction in machining of titanium grade 5 alloy using Physical Vapor Deposition (PVD) AlTiN coated carbide as a cutting insert (Pradhan \& Maity, 2018). They have optimized the machining parameters with desirability function approach, and found cutting speed is the most significant parameter. (Aouici et al., 2017) compared the TiN coated and uncoated ceramic tools especially on the cutting force in machining of AISI H11 steel by Taguchi method and RSM. Depth of cut was found as the most contributing factor on axial force. Uncoated carbide inserts show better performance in terms of cutting force and tool wear. Optimum conditions are estimated by using desirability function approach, quadratic models are estimated by RSM. Researchers have (Parida \& Routara, 2014) applied the multi-response optimization technique TOPSIS in machining of GFRP composite and this method led to more reliable solutions when compared to experimental results. Cutting speed is significant for SR and depth of cut is significant for the material removal rate (MRR). The authors (Balasubramaniyan Singaravel, 2015) simultaneously optimized microhardness, SR and MRR in machining of EN 25 steel with coated carbide using TOPSIS methodology. (Tic \& Steel, 2018) improved the surface quality and productivity of turning AISI D3 steel with mixed ceramic tools under dry condition. Feed rate is most significant for the SR and depth of cut for MRR, applied GRA for simultaneous optimization, grey relational grade was also improved and had a good agreement with the experimental value. (Kuntoglu et al., 2020) modelling the machining parameters in machining of AISI 5140 steel under dry conditions using coated carbide tools. Prediction of parameters estimated for SR and vibration for three components viz axial, radial and tangential showed a good agreement to the measured values. Feed rate is more effective for the SR and axial vibration followed by cutting-edge angle for radial vibration and cutting speed for tangential vibration. (Bouzid et al., 2018) optimized the flank wear in turning of AISI 304 stainless steel with multilayer $\mathrm{TiCN} / \mathrm{Al}_{2} \mathrm{O}_{3} / \mathrm{TiN}$ coated carbide using Desirability Function Analysis (DFA). Cutting time is identified as the most influential factor on SR and cutting speed significantly influences the tool lifespan. Increased cutting speed and feed rate reduces the tool life to about 77\%. Further, different optimization techniques as applied to dry turning are summarized in Table 1.

In the literature, Precise weight allocation for the output responses is not addressed; formulation of the inter-relationships between the responses is important when more responses are measured. In this paper, DEMATEL method is applied to dry machining of alloy steel to identify the relationships among the responses; CRITIC method is used to identify the weights for the responses, and TOPSIS employed for optimal process parameters estimation. This is a novel integrated MADM approach, which combines the three techniques: DEMATEL-CRITIC-TOPSIS.

Table 1

Summary of different optimization techniques in dry turning for alloy steels

\begin{tabular}{lll}
\hline Work material & DoE used & Optimization technique applied \\
\hline AISI H11 (Aouici et al., 2017) & L36 OA & Desirability function approach \\
\hline EN 25 steel (Singaravel et al., n.d.) & L18 OA & AHP-TOPSIS \\
AISI D3 steel (Tic \& Steel, 2018) & L18 OA & GRA \\
AISI 52100 steel (Alok \& Das, 2019) & 20 experiments, Central Composite Design (CCD) & RSM \\
AISI 304 stainless steel (Bouzid et al., 2018) & RSM - two full factorial designs - 27 runs & Desirability function approach \\
ultra-high-strength steel 300M (Wang \& Zhao, & 12 experiments with three levels of cutting speed (no & AHP-CRITIC \\
2016b) & DoE used) & TOPSIS \\
17-4 PH stainless steel (Sivaiah \& Uma, 2019) & L9 OA & \\
\hline
\end{tabular}

\section{Methodology}

The methodology employed for estimation of interrelationships between the output responses, weight and optimal parameters in machining of EN24 steel under dry condition is presented in Fig. 1. 


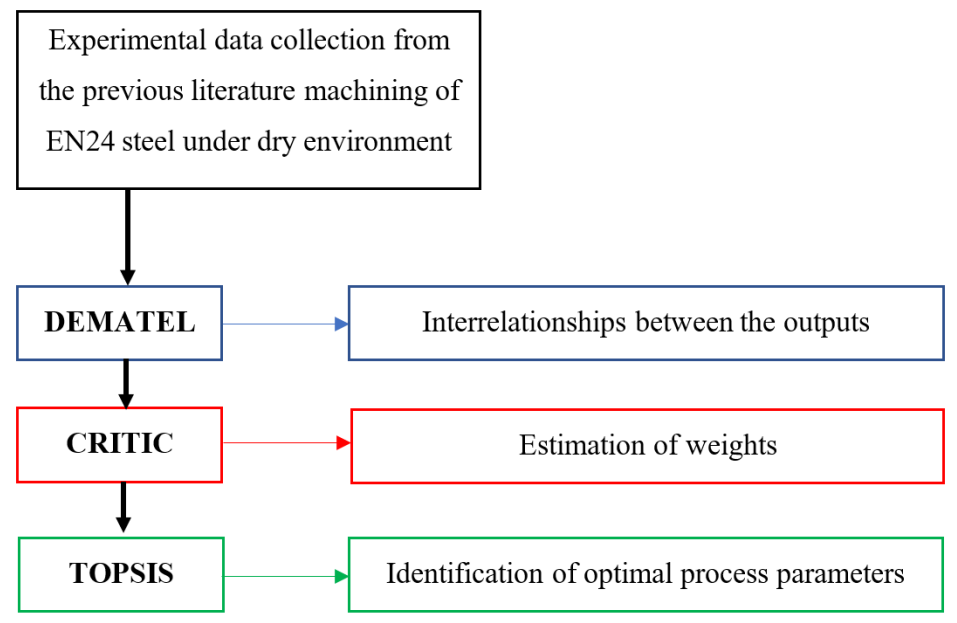

Fig. 1. Methodology employed

\section{MADM approaches}

This section presents the various approaches involved in MADM.

\subsection{DEMATEL method}

The DEMATEL method is widely used to identify the cause and effect of the responses. Major steps involved are identifying the threshold value, estimating the cause and effects and finally the formulation of the diagraph or causal relationships diagram

Step 1: Establishing the direct-relation matrix

The decision maker needs to establish the correlation between the criteria on a scale of 0 to 4 (Diakoulaki et al., 1995).

Step 2: Normalizing the direct-relation matrix

$\mathrm{Y}=\mathrm{k}$. A

$$
\text { where } k=\frac{1}{\max _{1 \leq i \leq n}\left(\sum_{j=1}^{n} a_{i j}\right)}(i, j=1,2, \ldots ., n)
$$

Step 3: Calculate the total-relation matrix $(\mathrm{T})$

$$
T=\left\lfloor t_{i j}\right\rfloor_{n \times n}(i, j=1,2, \ldots . ., n)
$$

where $T=Y(I-Y)^{-1}$

Here, $\mathrm{I}$ is identity matrix; $\mathrm{t}_{\mathrm{ij}}$ is indirect effect of the $\mathrm{i}^{\mathrm{th}}$ criterion on $\mathrm{j}^{\text {th }}$ criterion.

Step 4: Evaluate the sum of rows $(\mathrm{R})$ and columns $(\mathrm{C})$ of the matrix $\mathrm{T}$. The vectors $\mathrm{R}$ and $\mathrm{C}$ obtained using the equations

$$
\begin{aligned}
& R_{i}=\left[\sum_{j=1}^{n} t_{i j}\right]_{n x 1}=\left[t_{i}\right]_{n x 1}, \quad i=1,2, \ldots, n \\
& C_{j}=\left[\sum_{i=1}^{n} t_{i j}\right]_{1 x n}=\left[t_{j}\right]_{n x 1}, \quad i=1,2, \ldots, n
\end{aligned}
$$

Step 5: Derive the threshold value $(\alpha)$, which obtained by averaging of the elements in the T matrix. Here $N$ represents the number of elements in the T matrix. 


$$
\alpha=\frac{\sum_{i=1}^{n} \sum_{j=1}^{n}\left[t_{i j}\right]}{N}
$$

Step 6: Construction of the causal diagram

The prominence vector $\left(\mathrm{R}_{k}+\mathrm{C}_{\mathrm{k}}\right)$ on the horizontal axis when added with $\mathrm{R}$ and $\mathrm{C}$ values gives the importance of the criterion; the relation vector $\left(R_{k}-C_{k}\right)$ divides the cause group and effect group. If $\left(R_{k}-C_{k}\right)$ is positive then cause group, ( $R_{k}$ $-C_{k}$ ) is negative, then it is effect group. By establishing the causal diagram, the most important criteria for a problem can be identified.

\subsection{CRITIC Method}

The CRITIC method is an objective weight estimation based on the responses. After formulating the decision matrix, it is required to normalize and estimate the linear correlation coefficient between the criteria's. Finally, the individual weights of the responses are calculated.

Step 1: Determining the normalized decision making matrix using the Eq. (6)

$$
r_{i j}=\left\{\begin{array}{l}
\frac{x_{i j}-x_{j}^{\max }}{x_{j}^{\max }-x_{j}^{\min }} x_{i j} \text { is a beneficialattribute } \\
\frac{x_{j}^{\max }-x_{i j}}{x_{j}^{\max }-x_{j}^{\min }} x_{i j} \text { is a non }- \text { beneficialattribute }
\end{array}\right.
$$

Step 2: Estimating the criterion information

$$
C_{j}=\sigma_{j} \sum_{k=1}^{m} 1-r_{j k}
$$

Here $\sigma_{j}$ is the standard deviation of the each criterion and $r_{j k}$ linear correlation coefficient between the criteria's

Step 3: Determining the weights of the individual output

$$
W_{j}=\frac{C_{j}}{\sum_{j=1}^{n} C_{j}}
$$

\subsection{TOPSIS}

TOPSIS method uses the compromise ranking methodology and ranks the alternatives. Here the major step is to frame the positive and negative ideal solutions. TOPSIS method is explained as follows:

Step1: Decision matrix normalized based on the output responses

$$
R_{i j}=\frac{m_{i j}}{\sqrt{\sum_{j=1}^{M} m_{i j}^{2}}}
$$

Step 2: Estimated weights multiplied to the normalized decision matrix

$$
V_{i j}=w_{j}^{*} R_{i j}
$$

Step 3: Identifying the positive $\left(\mathrm{A}^{+}\right)$and negative $\left(\mathrm{A}^{-}\right)$ideal solutions

$$
\begin{aligned}
& A^{+}=\left\{v_{1}^{+}, v_{2}^{+}, \ldots ., v_{n}^{+}\right\} \\
& A^{-}=\left\{v_{1}^{-}, v_{2}^{-}, \ldots ., v_{n}^{-}\right\}
\end{aligned}
$$


Step 4: Estimating the separation measures for the alternatives

$$
D_{j}^{+}=\sqrt{\sum_{i=1}^{n}\left(v_{j}^{+}-v_{i j}\right)^{2}} ; \quad \overline{D_{j}}=\sqrt{\sum_{i=1}^{n}\left(v_{j}^{-}-v_{i j}\right)^{2}}
$$

Step 5: Calculating the Relative closeness value $\left(\mathrm{C}_{\mathrm{Ci}}\right)$

$$
C_{c i}=\frac{D_{j}^{-}}{D_{j}^{+}+D_{j}^{-}}
$$

Step 6: Ranking of the alternatives in the descending order of $\left(\mathrm{C}_{\mathrm{Ci}}\right)$.

\section{Parametric analysis of a dry machining on EN 24 alloy steel}

A hard turning of EN 24 alloy steel experiments are (A. Das et al., 2019) conducted on the specimen of 40mm diameter and $500 \mathrm{~mm}$ length under dry machining conditions. Based on Taguchi L9 Orthogonal Array (OA) with Cutting speed at three levels $(80,100,120 \mathrm{~m} / \mathrm{min})$, feed at three levels $(0.05,0.1,0.15 \mathrm{~mm} / \mathrm{rev})$ and depth of cut at three levels $(0.1,0.2,0.3 \mathrm{~mm})$ the layout for experimentation is created. The five output responses estimated are cutting force $\left(\mathrm{F}_{\mathrm{Z}}\right)(\mathrm{in} \mathrm{N})$, flank wear $\left(\mathrm{VB}_{\mathrm{C}}\right)$ (in $\mathrm{mm}$ ), crater wear width $\left(\mathrm{K}_{\mathrm{W}}\right)$ (in $\mathrm{mm}$ ), surface roughness $\left(\mathrm{R}_{\mathrm{a}}\right)$ (in $\mu \mathrm{m}$ ) and micro-hardness of the chip (MH) (in HV) which are summarized in the Table 2.

Table 2

\begin{tabular}{|c|c|c|c|c|c|c|c|c|}
\hline $\begin{array}{c}\text { Exp. } \\
\text { Run } \\
\text { no. }\end{array}$ & $\begin{array}{c}\text { Cutting } \\
\text { speed } \\
\text { (v) }\end{array}$ & Feed (f) & $\begin{array}{l}\text { Depth } \\
\text { of cut } \\
\text { (d) } \\
\end{array}$ & Fz (N) & $\begin{array}{c}\text { VBc } \\
(\mathrm{mm})\end{array}$ & $\begin{array}{c}\mathrm{Kw} \\
(\mathbf{m m})\end{array}$ & $\begin{array}{c}\text { Microhardness, } \\
\text { MH (HV) }\end{array}$ & $\begin{array}{c}\text { Surface roughness, } \\
\operatorname{Ra}(\mu \mathrm{m})\end{array}$ \\
\hline 1 & 1 & 1 & 1 & 104 & 0.18932 & 0.29341 & 280 & 1.20 \\
\hline 2 & 1 & 2 & 2 & 118 & 0.12932 & 0.24437 & 420 & 1.29 \\
\hline 3 & 1 & 3 & 3 & 159 & 0.11223 & 0.18621 & 519 & 1.34 \\
\hline 4 & 2 & 1 & 2 & 99 & 0.13996 & 0.24753 & 395 & 1.60 \\
\hline 5 & 2 & 2 & 3 & 123 & 0.05178 & 0.18762 & 530 & 1.67 \\
\hline 6 & 2 & 3 & 1 & 76 & 0.08036 & 0.23672 & 452 & 1.82 \\
\hline 7 & 3 & 1 & 3 & 119 & 0.16833 & 0.19902 & 458 & 2.10 \\
\hline 8 & 3 & 2 & 1 & 71 & 0.11132 & 0.2639 & 416 & 2.39 \\
\hline 9 & 3 & 3 & 2 & 88 & 0.13894 & 0.19832 & 516 & 2.61 \\
\hline
\end{tabular}

Experimental details of EN 24 machining using coated cermet under dry machining environment (A. Das et al., 2019)

In DEMATEL method, the initial step is to establish the direct relation matrix on the integer scale ranging from 0 to 4 . The developed direct-relation matrix for the five output responses shown in the Table 3. By using the Eq (1), the matrix then normalized as given in Table 4. Then, Eq. (2) applied to estimate the T matrix consequently the summation of rows and columns of the developed T matrix defined as $\mathrm{R}$ and $\mathrm{C}$ vectors by applying the Eq. (3) and Eq. (4) shown in Table 5. The net effect of the responses $(\mathrm{R}+\mathrm{C})$ and $(\mathrm{R}-\mathrm{C})$ is also estimated and grouped as cause and effect, as shown in Table 6 . The threshold value $(\alpha)$ is calculated using Eq. (5). Based on the cause and effect, the causal diagram is constructed and depicted in Fig 2. Flank wear has the highest net influence followed by surface roughness followed by cutting force in dry machining (turning) of EN 24 alloy steel.

Table 3

Formulated initial direct-relation matrix

\begin{tabular}{cccccc}
\hline Output responses & Fz & VBc & Kw & MH & Ra \\
\hline Fz & 0 & 3 & 2 & 3 & 3 \\
VBc & 3 & 0 & 1 & 2 & 3 \\
Kw & 2 & 1 & 3 & 0 & 3 \\
MH & 3 & 2 & 3 & 3 & 1 \\
Ra & 3 & 2 & & 0 & 0 \\
\hline
\end{tabular}


Table 4

Normalized values for the direct-relation matrix

\begin{tabular}{cccccc}
\hline Output responses & Fz & VBc & Kw & MH & Ra \\
\hline Fz & 0 & 0.272727 & 0.181818 & 0.272727 & 0.272727 \\
VBc & 0.272727 & 0 & 0.090909 & 0.181818 & 0.272727 \\
Kw & 0.181818 & 0.090909 & 0 & 0.090909 & 0.272727 \\
MH & 0.272727 & 0.181818 & 0.272727 & 0 & 0.090909 \\
Ra & 0.272727 & 0.181818 & 0.272727 & 0.272727 & 0 \\
\hline
\end{tabular}

Table 5

Total relational-matrix for the output responses

\begin{tabular}{cccccc}
\hline Output responses & Fz & VBc & Kw & MH & Ra \\
\hline Fz & $1.418133^{*}$ & $1.322915^{*}$ & $1.368454^{*}$ & $1.440178^{*}$ & $1.524426^{*}$ \\
VBc & $1.452701^{*}$ & 0.971393 & $1.14941^{*}$ & $1.229787^{*}$ & $1.359118^{*}$ \\
Kw & $1.136204^{*}$ & 0.855682 & 0.850714 & 0.94289 & $1.133699^{*}$ \\
MH & $1.379839^{*}$ & 1.065618 & $1.215897^{*}$ & 1.002587 & $1.180604^{*}$ \\
Ra & $1.609812^{*}$ & $1.243221^{*}$ & $1.418547^{*}$ & $1.419685^{*}$ & $1.294039^{*}$ \\
\hline
\end{tabular}

$*_{\text {tij }}>1.0916$

Table 6

Computation of vectors $\mathrm{D}$ and $\mathrm{K}$ and net effects of response

\begin{tabular}{cccccc}
\hline Output responses & Rk & Ck & R+C & R $-\mathbf{C}$ & Criteria group \\
\hline Fz & 7.074105 & 6.996688 & 14.07079 & 0.077417 & Cause \\
VBc & 6.162409 & 5.458828 & 11.62124 & 0.703581 & Cause \\
Kw & 4.919189 & 6.003022 & 10.92221 & -1.08383 & Effect \\
MH & 5.844546 & 6.035127 & 11.87967 & -0.19058 & Effect \\
Ra & 6.985303 & 6.491886 & 13.47719 & 0.493418 & Cause \\
\hline
\end{tabular}

The threshold value $(\alpha)$ is 1.0916 which is obtained by averaging the all the elements in the T matrix of Table 5 . In the Table 5 the $t_{i j} \times$ represents the elements of $T$ matrix which are greater than 1.0916, it represents the significant interaction between the two output responses. For example $t_{12} \times(1.322915)>\alpha(1.0916)$, so in the diagraph an arrow shows the interaction of cutting force and micro hardness (unidirectional) as depicted in the Fig. 3. There are further bi-directional interactions between the output responses like flank wear to cutting force, cutting force to surface roughness, surface roughness to micro hardness, cutting force to crater wear width and cutting force to micro hardness.

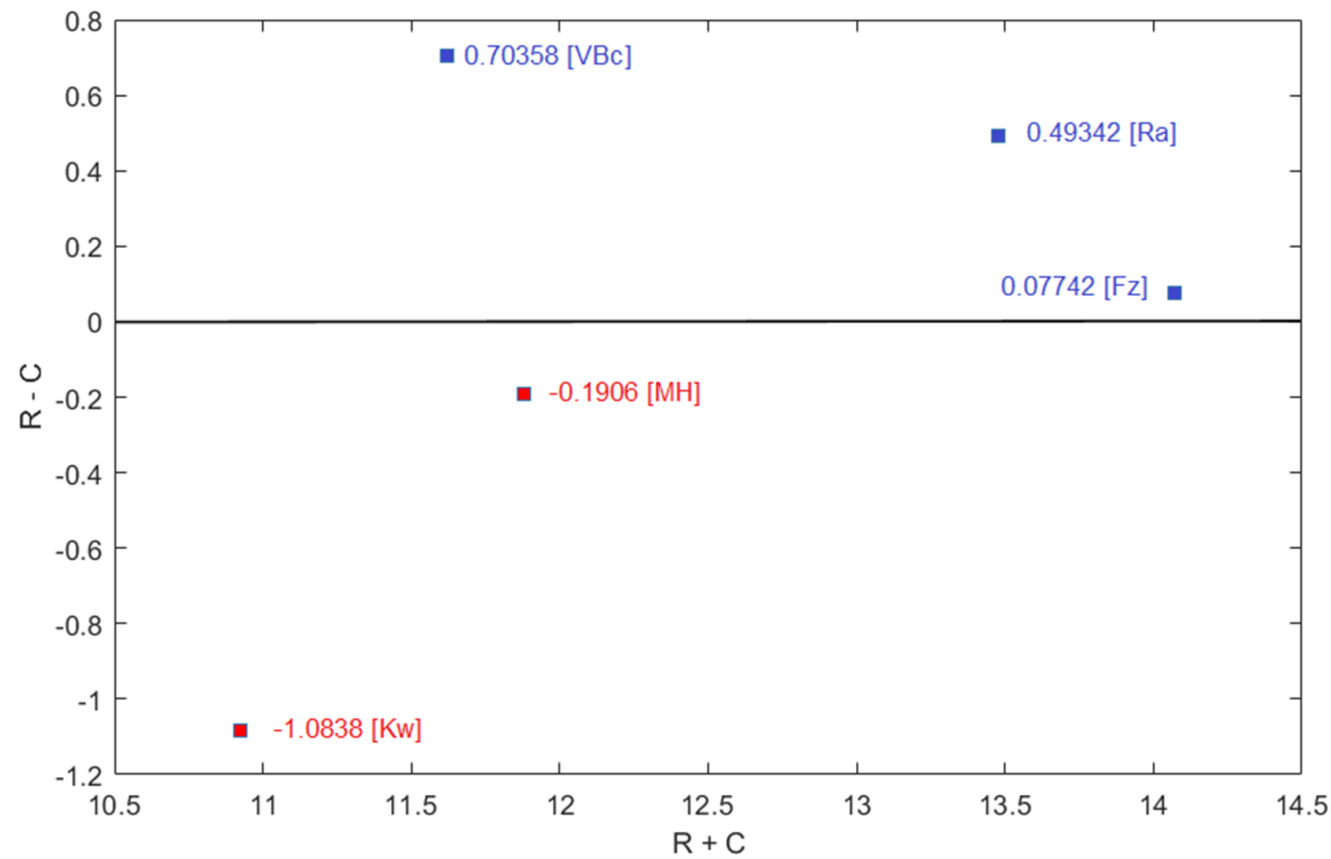

Fig. 2. DEMATEL causal diagram for the output responses 


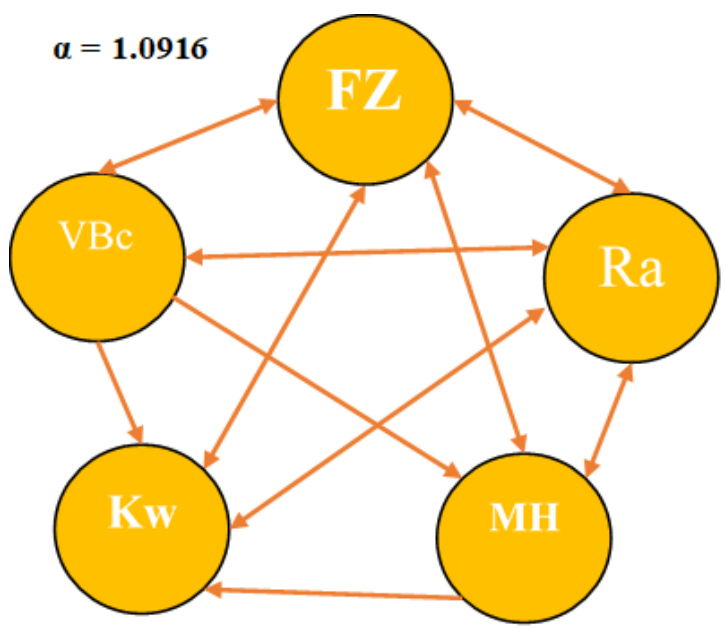

Fig. 3. DEMATEL diagraph for responses

In MCDM problems, weights of the responses play important role; for this purpose CRITIC methodology is employed. The five output responses from the Table 2 is normalized using the Eq. (6), the normalized values are shown in Table 7. The criterion information calculated using Eq. (7) and correlation values are tabulated in table 8. The weights of the five output responses are estimated using Eq. (8) and are presented in the last column of Table 9.

Table 7

Normalized values of output responses by CRITIC method

\begin{tabular}{cccccc}
\hline Exp. Run no. & $\mathrm{Fz}$ & $\mathrm{VBc}$ & $\mathrm{Kw}$ & $\mathrm{MH}$ & $\mathrm{Ra}$ \\
\hline $\mathbf{1}$ & 0.625 & 0 & 0 & 0 & 1 \\
$\mathbf{2}$ & 0.465909 & 0.436237 & 0.457463 & 0.56 & 0.93617 \\
$\mathbf{3}$ & 0 & 0.560491 & 1 & 0.956 & 0.900709 \\
$\mathbf{4}$ & 0.681818 & 0.358877 & 0.427985 & 0.46 & 0.716312 \\
$\mathbf{5}$ & 0.409091 & 1 & 0.986847 & 1 & 0.666667 \\
$\mathbf{6}$ & 0.943182 & 0.792206 & 0.528825 & 0.688 & 0.560284 \\
$\mathbf{7}$ & 0.454545 & 0.15261 & 0.880504 & 0.712 & 0.361702 \\
$\mathbf{8}$ & 1 & 0.567108 & 0.27528 & 0.544 & 0.156028 \\
$\mathbf{9}$ & 0.806818 & 0.366293 & 0.887034 & 0.944 & 0 \\
\hline
\end{tabular}

Table 8

Correlation coefficient of the output responses

\begin{tabular}{cccccc}
\hline & $\mathrm{Fz}$ & $\mathrm{VBc}$ & $\mathrm{KW}$ & $\mathrm{MH}$ & $\mathrm{Ra}$ \\
\hline $\mathrm{Fz}$ & 1 & 0.00311 & -0.5283 & -0.31981 & -0.57292 \\
$\mathrm{VBc}$ & 0.00311 & 1 & 0.434201 & 0.645073 & -0.07848 \\
$\mathrm{Kw}$ & -0.5283 & 0.434201 & 1 & 0.936909 & -0.25513 \\
$\mathrm{MH}$ & -0.31981 & 0.645073 & 0.936909 & 1 & -0.38717 \\
$\mathrm{Ra}$ & -0.57292 & -0.07848 & -0.25513 & -0.38717 & 1 \\
\hline
\end{tabular}

Table 9

Weights for the output responses estimated by using CRITIC method

\begin{tabular}{ccc}
\hline & $\mathrm{Cj}$ & $\mathrm{Wj}$ \\
\hline $\mathrm{Fz}$ & 1.673678 & 0.25214 \\
$\mathrm{VBc}$ & 0.91627 & 0.138037 \\
$\mathrm{Kw}$ & 1.200947 & 0.180923 \\
$\mathrm{MH}$ & 0.979384 & 0.147545 \\
$\mathrm{Ra}$ & 1.8676 & 0.281355 \\
\hline
\end{tabular}


For finding the optimal set of parameters using TOPSIS, Table 2 output responses normalized with Eq. (9). The weights estimated using CRITIC method are utilized here and multiplied with the normalized values using the Eq. (10). Estimation of positive and negative ideal solutions is obtained by using Eq. (11). Further the separation measures using Eq. (12) and the closeness coefficient using Eq. (13). Now, the ranking of alternatives in descending order is carried out based on the closeness coefficient and ranking is established to identify the optimal parameters, which is presented in Table 10.

Table 10

$\mathrm{Dj}^{+}, \mathrm{Dj}^{-}, \mathrm{C}_{\mathrm{Ci}}$ and Rank by using the TOPSIS

\begin{tabular}{ccccc}
\hline Exp. Run no. & $\mathrm{Dj}+$ & $\mathrm{Dj}-$ & $\mathrm{C}_{\mathrm{Ci}}$ & Rank \\
\hline $\mathbf{1}$ & 0.067199 & 0.083348 & 0.553632 & 5 \\
$\mathbf{3}$ & 0.049444 & 0.079748 & 0.617284 & 3 \\
$\mathbf{4}$ & 0.071254 & 0.079931 & 0.528697 & 6 \\
$\mathbf{5}$ & 0.048115 & 0.073328 & 0.603805 & 4 \\
$\mathbf{6}$ & 0.046584 & 0.083134 & 0.64088 & 2 \\
$\mathbf{7}$ & 0.03688 & 0.087924 & 0.704498 & $\mathbf{1}$ \\
$\mathbf{8}$ & 0.072235 & 0.051577 & 0.416573 & 9 \\
$\mathbf{9}$ & 0.068418 & 0.075712 & 0.525304 & 7 \\
\hline
\end{tabular}

From TOPSIS, run number six is identified as optimum parameter level combinations where in cutting speed is $100 \mathrm{~m} / \mathrm{min}$, feed is $0.15 \mathrm{~mm} / \mathrm{rev}$ and depth of cut is $0.1 \mathrm{~mm}$ under dry machining. In dry machining, the depth of cut influences the cutting force, feed influences the flank wear, depth of cut influence the crater wear, feed influences the micro hardness of chip, and cutting speed influences the surface roughness. The tool is continuously in contact with the work piece in turning operation, where the tool wear is more profound. In dry machining, the tool wears out quickly because of the absence of coolant in the cutting zone. The surface roughness of the material affects further because of tool wear. The worn out particles damage the surface integrity of the work piece. If the cutting forces in the cutting zone are reduced the work piece will have a better surface finish. In dry machining, the tool wear, surface roughness and cutting forces are the main factors in the machining of alloy steels. As the hardness of the chip increases, there will be an increase in tool wear too.

\section{Conclusions}

In this work, a Hybrid technique by combining the DEMATEL-CRITIC-TOPSIS methods has been applied to estimate the interrelationship between the output parameters and finally we have found the optimal parametric combination in machining on EN 24 alloy steel under the dry machining. The cause and effects have been identified by DEMATEL as cutting forces, flank wear, and surface roughness. All the parameters finally affect the surface roughness of the machined part, and CRITIC method has shown the highest weightage to surface roughness. Finally, TOPSIS determined the optimal combination of parameters in dry machining of EN 24 alloy steel. The data obtained for verifying the proposed model are collected from the literature, as there is no scope for conducting the confirmation test. This method can be applied to other machining processes to estimate optimal parameters and improve the performance of machining.

\section{References}

Akkuş, H., \& Yaka, H. (2021). Experimental and statistical investigation of the effect of cutting parameters on surface roughness, vibration and energy consumption in machining of titanium 6Al-4V ELI (grade 5) alloy. Measurement: Journal of the International Measurement Confederation, 167(June 2020).

Alok, A., \& Das, M. (2019). Multi-objective optimization of cutting parameters during sustainable dry hard turning of AISI 52100 steel with newly develop HSN 2 -coated carbide insert. Measurement, 133, 288-302.

Aouici, H., Khellaf, A., Smaiah, S., Elbah, M., Fnides, B., \& Yallese, M. A. (2017). Comparative assessment of coated and uncoated ceramic tools on cutting force components and tool wear in hard turning of AISI H11 steel using Taguchi plan and RMS. Sadhana.

Balasubramaniyan Singaravel, T. S. (2015). Optimization of machining parameters in turning operation using combined TOPSIS and AHP method. Tehnicki Vjesnik - Technical Gazette, 22(6).

Bouzid, L., Berkani, S., Athmane, M., \& Girardin, F. (2018). Estimation and optimization of flank wear and tool lifespan in finish turning of AISI 304 stainless steel using desirability function approach. 9, 349-368.

Das, A., Tirkey, N., Kumar, S., Sudhansu, P., Das, R., Chip, A. Á., Flank, Á., \& Cermet, Á. (2019). A Comparison of Machinability in Hard Turning of EN-24 Alloy Steel Under Mist Cooled and Dry Cutting Environments with a Coated Cermet Tool. Journal of Failure Analysis and Prevention, 19(1), 115-130.

Das, P. P., \& Chakraborty, S. (2020). Parametric analysis of a green electrical discharge machining process using DEMATEL and SIR methods. Opsearch, 57(2), 513-540.

Diakoulaki, D., Mavrotas, G., \& Papayannakis, L. (1995). Determining objective weights in multiple criteria problems: The critic method. Computers and Operations Research, 22(7), 763-770. 
Gaitonde, V. N., Karnik, S. R., \& Davim, J. P. (2009). Multiperformance optimization in turning of free-machining steel using taguchi method and utility concept. Journal of Materials Engineering and Performance, 18(3), 231-236.

Jozić, S., Dumanić, I., \& Bajić, D. (2020). Experimental analysis and optimization of the controllable parameters in turning of en aw-2011 alloy; dry machining and alternative cooling techniques. Facta Universitatis, Series: Mechanical Engineering, 18(1), 013.

Julong, D. (1988). Introduction to Grey System Theory.

Kaliszewski, I., \& Podkopaev, D. (2016). Simple additive weighting —A metamodel for multiple criteria decision analysis methods. Expert Systems with Applications, 54, 155-161.

Kuntoglu, M., Pimenov, D. Y., Giasin, K., \& Mikolajczyk, T. (2020). Modeling of Cutting Parameters and Tool Geometry. September.

Lai, Y.-J., Liu, T.-Y., \& Hwang, C.-L. (1994). TOPSIS for MODM. European Journal of Operational Research, 76(3), 486-500.

Mir, M. J., \& Wani, M. F. (2018). Modelling and analysis of tool wear and surface roughness in hard turning of AISI D2 steel using response surface methodology. 9, 63-74.

Parida, A. K., \& Routara, B. C. (2014). Multiresponse Optimization of Process Parameters in Turning of GFRP Using TOPSIS Method. International Scholarly Research Notices, 2014, 1-10.

Pradhan, S., \& Maity, K. (n.d.). Investigation of surface roughness, tool wear and chip reduction coefficient during machining of titanium alloy with PVD Al-Ti-N coating carbide insert. 2-5.

Rao, R. V., \& Patel, B. K. (2010). Decision making in the manufacturing environment using an improved PROMETHEE method. International Journal of Production Research, 48(16), 4665-4682.

Saaty. (2002). The Analytic Hierarchy Process ( AHP) and the Analytic Network Process ( ANP) for Decision Making Decision Making involves setting priorities and the AHP / ANP is the methodology for doing. 1-109.

Sabiya, K., Shilpa, M., Appaiah. S. (2019). Scrap reduction in TMT reinforced bar production by the application of lean techniques. International Journal of Recent Technology and Engineering, 8(2), 3483-3487.

Shastri, A., Nargundkar, A., Kulkarni, A. J., \& Benedicenti, L. (2021). Optimization of process parameters for turning of titanium alloy (Grade II) in MQL environment using multi-CI algorithm. SN Applied Sciences, 3(2).

Shilpa, M., Prakash, G.S., Shivakumar, M.R. (2020). A combinatorial approach to optimize the properties of green sand used in casting mould, Materials Today: Proceedings, 39, 1509-1514.

Si, S. L., You, X. Y., Liu, H. C., \& Zhang, P. (2018). DEMATEL Technique: A Systematic Review of the State-of-the-Art Literature on Methodologies and Applications. Mathematical Problems in Engineering, 2018(1).

Singaravel, B., Vjesnik, T. S.-T., \& 2015, undefined. (n.d.). Optimization of machining parameters in turning operation using combined TOPSIS and AHP method. Pdfs.Semanticscholar.Org. Retrieved May 29, 2018, from

Sivaiah, P., \& Uma, B. (2019). Multiobjective optimization of sustainable turning process using TOPSIS method. Emerging Materials Research, 8(4), 686-695.

Tic, A. O., \& Steel, A. D. (2018). Simultaneous improvement of surface quality and productivity using grey relational analysis based Taguchi design for turning couple ( AISI D3 steel / mixed ceramic tool. 9, 173-194.

Venkata Ajay Kumar, G., Shilpa, M., Purander, U.S., Madhoo, G., Asokan, V. (2019). Multi-objective optimization of machining process parameters in wire-cut electric discharge machining of inconel x750 alloy by combinatorial approach, Materials Science Forum, 969, 781-786.

Viswanathan, R., Ramesh, S., \& Subburam, V. (2018). Measurement and optimization of performance characteristics in turning of $\mathrm{Mg}$ alloy under dry and MQL conditions. Measurement: Journal of the International Measurement Confederation, 120(February), 107-113.

Wang, D., \& Zhao, J. (2016a). Design optimization of mechanical properties of ceramic tool material during turning of ultra-high-strength steel 300M with AHP and CRITIC method. International Journal of Advanced Manufacturing Technology, 84(9-12), 2381-2390.

Wang, D., \& Zhao, J. (2016b). Design optimization of mechanical properties of ceramic tool material during turning of ultra-high-strength steel 300M with AHP and CRITIC method. The International Journal of Advanced Manufacturing Technology, 84(9-12), 2381-2390. 
(C) 2022 by the authors; licensee Growing Science, Canada. This is an open access article distributed under the terms and conditions of the Creative Commons Attribution (CC-BY) license (http://creativecommons.org/licenses/by/4.0/). 